(Supporting Information)

\title{
Heteroatom Tracing Reveals the 30-Atom Au-Ag Bimetallic Nanocluster as a Dimeric Structure
}

\author{
Yingwei Li, ${ }^{+, 1}$ Michael G. Taylor, ${ }^{+, 2}$ Tian-Yi Luo, ${ }^{3}$ Yongbo Song, ${ }^{1}$ Nathaniel L. Rosi, ${ }^{3}$ \\ Giannis Mpourmpakis, ${ }^{*}, 2$ and Rongchao Jin ${ }^{*}, 1$ \\ ${ }^{1}$ Department of Chemistry, Carnegie Mellon University, Pittsburgh, Pennsylvania 15213, United States \\ 2Department of Chemical Engineering, University of Pittsburgh, Pittsburgh, Pennsylvania 15261, United \\ States \\ ${ }^{3}$ Department of Chemistry, University of Pittsburgh, Pittsburgh, Pennsylvania 15260, United States
}

+These authors contribute equally to the work.

*Email: rongchao@andrew.cmu.edu,and gmpourmp@pitt.edu

\section{Experimental}

\section{Chemicals}

Tetrachloroauric (III) acid $\left(\mathrm{HAuCl}_{4} \cdot 3 \mathrm{H}_{2} \mathrm{O}, 99.999 \%\right.$ metal basis, Aldrich), silver nitrate $\left(\mathrm{AgNO}_{3},>99.0 \%\right.$, Aldrich), sodium borohydride $\left(\mathrm{NaBH}_{4}, 99.99 \%\right.$ metal basis, Aldrich), 2-methyl-2propanethiol (HS- ${ }^{-} \mathrm{C}_{4} \mathrm{H}_{9}, 99 \%$, Aldrich), tetrahydrofuran (THF, HPLC grade, $99.9 \%$, Aldrich), ethanol (HPLC grade, Aldrich), methanol (HPLC grade, 99.9\%, Aldrich), and dichloromethane (DCM, HPLC grade, $99.9 \%$, Aldrich), were used as received.

\section{Synthesis}

$89 \mathrm{mg} \mathrm{HAuCl} 4 \cdot 3 \mathrm{H}_{2} \mathrm{O}, 4.8 \mathrm{mg} \mathrm{AgNO}_{3}$ (dissolved first in $1 \mathrm{~mL}$ of nano-pure water) with $\mathrm{Au} / \mathrm{Ag}$ molar ratio $=8: 1$, and $82 \mu \mathrm{L} 2$-methyl-2-propanethiol were mixed in THF and vigorously stirred for 30 min, followed by addition of a freshly prepared aqua solution of $\mathrm{NaBH}_{4}(100 \mathrm{mg}$ in $5 \mathrm{~mL})$ was directly added. After $1 \mathrm{~h}$, THF was evaporated and the crude product was washed by methanol thoroughly, extracted by acetone, further dissolved in a mixture of $3 \mathrm{~mL}$ toluene and $5 \mathrm{~mL} 2$ methyl-2-propanethiol, and reacted overnight at $45^{\circ} \mathrm{C}$. After being repeatedly washed by methanol and extracted by DCM, a mixture of $\mathrm{Au}_{30-x} \mathrm{Ag}_{x}\left(\mathrm{~S}_{-}{ }^{t} \mathrm{C}_{4} \mathrm{H}_{9}\right)_{18}$ and $\mathrm{Au}_{21-x} \mathrm{Ag}_{x}\left(\mathrm{~S}^{-t} \mathrm{C}_{4} \mathrm{H}_{9}\right)_{15}$ was obtained (Figure S1a). But after diffusion ethanol into the DCM solution of the mixture, only the portion of $\mathrm{Au}_{30-x} \mathrm{Ag}_{x}\left(\mathrm{~S}-{ }^{-t} \mathrm{C}_{4} \mathrm{H}_{9}\right)_{18}$ was crystallized (Figure $\left.\mathrm{S} 1 \mathrm{~b}\right)$, leaving $\mathrm{Au}_{21-x} \mathrm{Ag}_{x}\left(\mathrm{~S}-{ }^{t} \mathrm{C}_{4} \mathrm{H}_{9}\right)_{15}$ behind.

When the reaction was conducted at room temperature, and other conditions were kept the same, only $\mathrm{Au}_{21-x} \mathrm{Ag}_{x}\left(\mathrm{~S}-{ }^{t} \mathrm{C}_{4} \mathrm{H}_{9}\right)_{15}(x=2-4)$ was obtained (Figure $\left.\mathrm{S} 1 \mathrm{c}\right)$, and further purified by crystallization (solvent evaporation of methanol into a DCM solution of the clusters) as shown in Figure S1d.

Homogold $\mathrm{Au}_{21}\left(\mathrm{~S}-{ }^{-t} \mathrm{C}_{4} \mathrm{H}_{9}\right)_{15}$ and $\mathrm{Au}_{30}\left(\mathrm{~S}-{ }^{t} \mathrm{C}_{4} \mathrm{H}_{9}\right)_{18} \mathrm{NCs}$ were reproduced according to the literatures. ${ }^{\mathrm{s} 1, \mathrm{~s} 2}$

For the time dependent experiments monitored by MALDI-MS, different molar ratios of $\mathrm{Au} / \mathrm{Ag}$ $(10: 1$, or $15: 1)$, different toluene/HS- ${ }^{-} \mathrm{C}_{4} \mathrm{H}_{9}$ volume ratios $(1: 1.5$, or $1: 3)$, and different temperatures for ligand etching $\left(45^{\circ} \mathrm{C}\right.$ or room temperature) were carried out. 


\section{Characterization of the gold nanoclusters}

UV-vis spectra of the clusters were measured on a Hewlett-Packard Agilent 8453 diode array spectrophotometer at room temperature. ESI mass spectra were recorded using a Waters Q-TOF mass spectrometer equipped with Z-Spray Source.

\section{X-ray Crystallographic Determination}

Single crystal X-ray diffraction data of $\mathbf{A u}_{27.32} \mathbf{A g}_{2.69}\left(\mathbf{S}_{-}{ }^{t} \mathbf{C}_{4} \mathbf{H}_{9}\right)_{18}$ was collected on a Bruker X8 Prospector Ultra equipped with an Apex II CCD detector and an I $\mu$ S micro-focus $\mathrm{CuK}_{\alpha} \mathrm{X}$-ray source $(\lambda=1.54178 \AA)$. A piece of dark red block crystal with dimensions $0.2 \times 0.04 \times 0.02 \mathrm{~mm}$ was mounted onto a MiTeGen MicroMount. Data collection was performed at $230 \mathrm{~K}$. A monoclinic unit cell with $a=15.2662(5) \AA, b=51.5233(15) \AA, c=17.4781(5) \AA, \alpha=90^{\circ}, \beta=90.777(2)^{\circ}, \gamma=90^{\circ}$ was determined using the least-square refinement. The frames were integrated with the Bruker SAINTs3 software package. 102654 reflections in the range $3.43^{\circ}<2 \theta<102.71^{\circ}$ were found, of which 14920 were independent (average redundancy 6.88, completeness $=100 \%, \mathrm{R}_{\text {int }}=15.33 \%, \mathrm{R}_{\text {sigma }}=$ $9.24 \%)$ Data were corrected for absorption effects using SADABSs3 Multi-Scan method $\left(\mathrm{T}_{\min }=0.148\right.$, $\mathrm{T}_{\max }=0.750$ ). Space group $P 2_{1} / \mathrm{n}$ was determined based on systematic absences. The structure was solved by intrinsic phasing using the Bruker SHELXTs4 ${ }^{3}$ software package and refined by full-matrix least-squares on $\mathrm{F}^{2}$ using SHELXL in Olex2..55,s6 The asymmetric unit contains one complete $\mathbf{A u}_{27.32} \mathbf{A g}_{2.69}\left(\mathbf{S}^{-} \mathbf{C}_{4} \mathbf{H}_{9}\right)_{18}$ cluster. All the metal and $\mathrm{S}$ atoms were found directly. Remaining nonhydrogen atoms were generated via subsequent difference Fourier syntheses. Occupancies of $\mathrm{Au}$ and $\mathrm{Ag}$ sites were refined using free variables, EXYZ and EADP. Au, Ag, S and $\mathrm{C}$ atoms were refined with anisotropic displacement parameters. SIMU, RIGU restraints were applied to refine the t-butyl groups. Idealized hydrogen atom positions were calculated.

\section{DFT Calculations}

DFT calculations were performed using the BP-86 functional with the def2-SV(P)s7 basis set accelerated with the resolution of identities ${ }^{88,59}$ approximation. All cluster structures were taken from experimental crystal structures ${ }^{\mathrm{s} 1, \mathrm{~s} 10-\mathrm{s} 17]}$ and ligands were substituted with methyl groups $(\mathrm{R}=$ $\left.\mathrm{CH}_{3}\right)$ before being relaxed with a quasi-newton-Raphson method. In $\mathrm{Au}_{21-x} \mathrm{Ag}_{x}\left(\mathrm{~S}^{-}{ }^{t} \mathrm{C}_{4} \mathrm{H}_{9}\right)_{15}$, only one specific position can be $100 \%$ occupied by Ag, while additional Ag would have a distribution with low $\%$ at other positions in the NC, and the absorption spectra do not change much with multiple Ag doping compared to just one.[1] Thus, simulation is carried out on $\mathrm{Au}_{20} \mathrm{Ag}_{1}\left(\mathrm{~S}_{-}-\mathrm{CH}_{3}\right)_{15}$. As for $\mathrm{Au}_{30}$ ${ }_{x} \mathrm{Ag}_{x}\left(\mathrm{~S}-{ }^{t} \mathrm{C}_{4} \mathrm{H}_{9}\right)_{18}(x=2-4)$, the two positions with highest $\mathrm{Ag}$ occupancies $(87 \%$ and $97 \%)$ are assigned as $100 \% \mathrm{Ag}$, and the rest as $\mathrm{Au}$, hence, $\mathrm{Au}_{28} \mathrm{Ag}_{2}\left(\mathrm{~S}-\mathrm{CH}_{3}\right)_{18}$ in calculation.

After relaxation, vibrational modes over the full clusters were calculated and it was verified that no relaxed cluster contained negative frequencies. Vibrational modes were then used to calculate Gibbs free energies for each structure at $\mathrm{T}=298.5 \mathrm{~K}$ as outlined in previous work. ${ }^{\text {s18 }}$ Although ligand effects are shown to be non-negligible in differentiating different isomers of cluster structures, here, dimerization effects represent cluster size shifts and are dominated largely by Au-S framework energetics rather than ligand-ligand energetics. Additionally, full first principle calculated free energies can be computationally intractable with full ligands (high computational cost). For TDDFT calculations, the lowest 800 singlet-to-singlet excitations (of interest for these clusters ${ }^{119}$ ) were simulated for each of the $\mathrm{Au}_{20} \mathrm{Ag}_{1}\left(\mathrm{~S}-\mathrm{CH}_{3}\right)_{15}$ and $\mathrm{Au}_{28} \mathrm{Ag}_{2}\left(\mathrm{~S}-\mathrm{CH}_{3}\right)_{18}$ nanoclusters. The reported TDDFT spectra were generated from stick spectra using gaussian broadening with a half-width maxima of $0.1 \mathrm{eV}$ as reported in other work. s19 $^{2}$ 


\section{Supporting Figures}

As synthesized

Crystallized

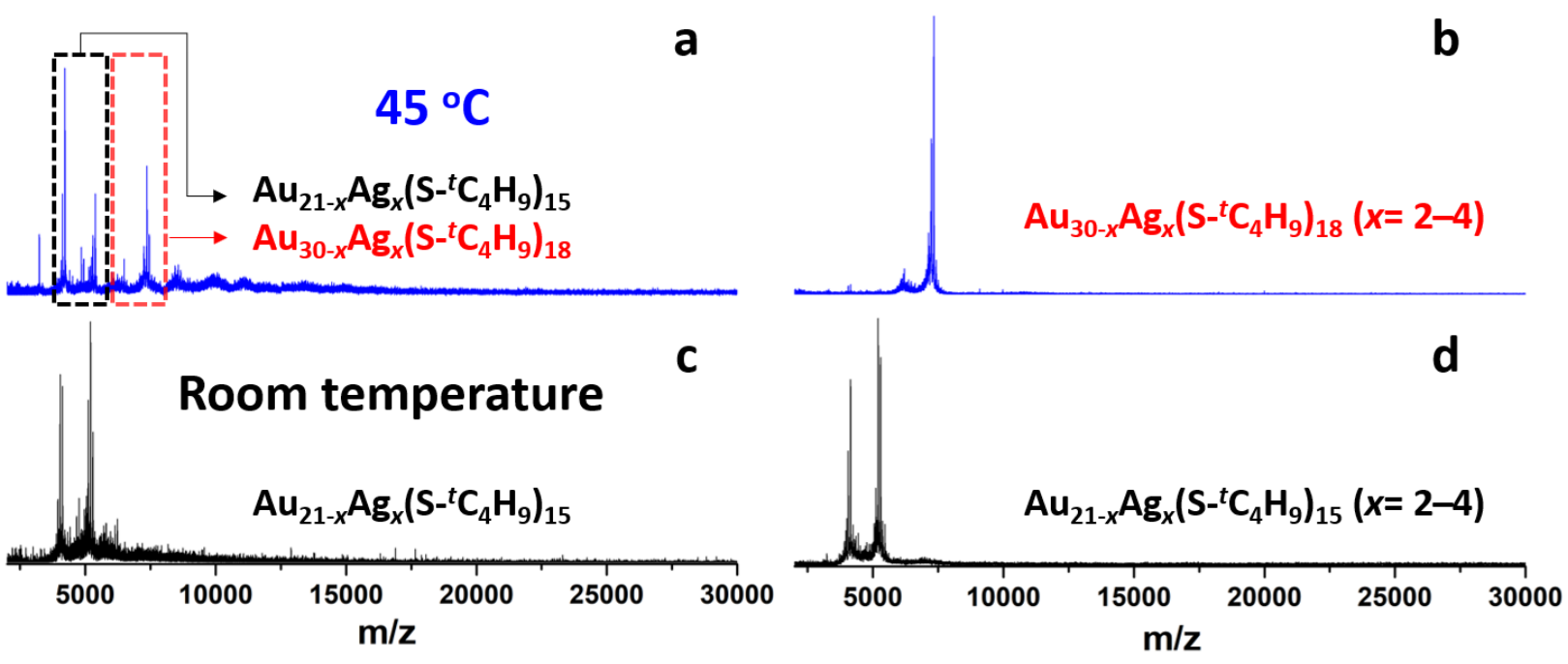

Figure S1. MALDI-MS spectra of (a) the mixture of $\mathrm{Au}_{21-x} \mathrm{Ag}_{x}\left(\mathrm{~S}-\mathrm{t}_{4} \mathrm{H}_{9}\right)_{15}$ and $\mathrm{Au}_{30-x} A g_{x}\left(\mathrm{~S}-{ }^{-t} \mathrm{C}_{4} \mathrm{H}_{9}\right)_{18}$ synthesized at $45{ }^{\circ} \mathrm{C}$, and (b) $\mathrm{Au}_{30-x} \mathrm{Ag}_{x}\left(\mathrm{~S}-{ }^{t} \mathrm{C}_{4} \mathrm{H}_{9}\right)_{18}(x=2-4)$ crystals (of note: $\mathrm{Au}_{21-x} \mathrm{Ag}_{x}$ NCs were left in the supernatant); (c) $\mathrm{Au}_{21-x} \mathrm{Ag}_{x}\left(\mathrm{~S}-{ }^{t} \mathrm{C}_{4} \mathrm{H}_{9}\right)_{15}$ synthesized at room temperature, and (d) $\mathrm{Au}_{21-x} \mathrm{Ag}_{x}(\mathrm{~S}-$ $\left.{ }^{t} \mathrm{C}_{4} \mathrm{H}_{9}\right)_{15}(x=2-4)$ crystals.

Table S1. Atomic percentage of $\mathrm{Au} / \mathrm{Ag}$ in $\mathrm{Au}_{30-x} \mathrm{Ag}_{x}\left(\mathrm{~S}-{ }^{-t} \mathrm{C}_{4} \mathrm{H}_{9}\right)_{18}$ with $\mathrm{x}=2-4$ measured by ESI-MS (crystallographically avg. $x=2.69$ ). The Ag dominant sites are highlighted in red.

\begin{tabular}{ccccccccc}
\hline Label & $\mathbf{7}$ & $\mathbf{1 9}$ & $\mathbf{2 1}$ & $\mathbf{2 2}$ & $\mathbf{2 3}$ & $\mathbf{2 4}$ & $\mathbf{2 6}$ & $\mathbf{2 7}$ \\
\hline $\mathrm{Au}$ & 0.13 & $\mathbf{0 . 8 0}$ & $\mathbf{0 . 8 8}$ & 0.03 & $\mathbf{0 . 8 6}$ & $\mathbf{0 . 8 6}$ & $\mathbf{0 . 8 6}$ & $\mathbf{0 . 9 0}$ \\
$\mathrm{Ag}$ & $\mathbf{0 . 8 7}$ & 0.20 & 0.12 & $\mathbf{0 . 9 7}$ & 0.14 & 0.14 & 0.14 & 0.10 \\
\hline
\end{tabular}

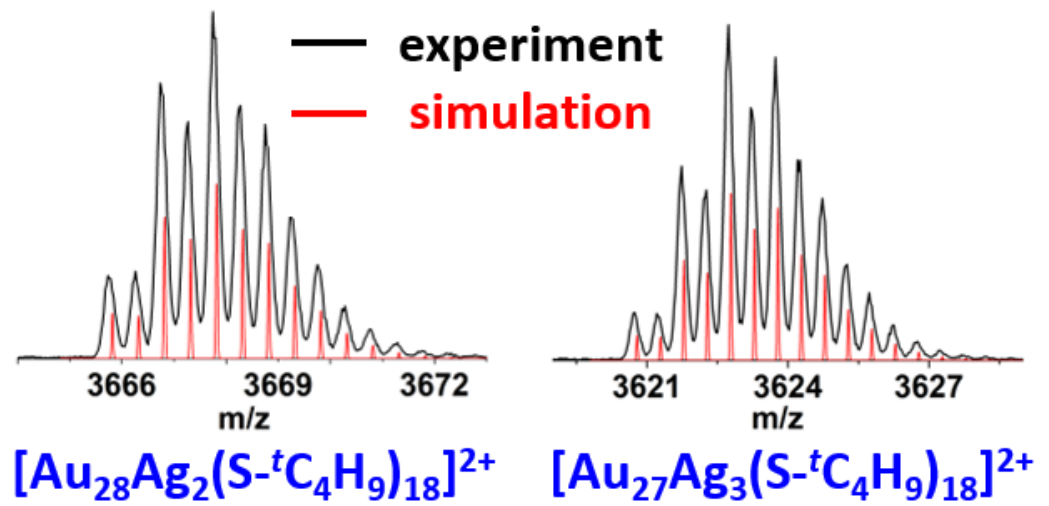

Figure S2. The isotope patterns of $\left[\mathrm{Au}_{28} \mathrm{Ag}_{2}\left(\mathrm{~S}-{ }^{t} \mathrm{C}_{4} \mathrm{H}_{9}\right)_{18}\right]^{2+}$ and $\left[\mathrm{Au}_{27} \mathrm{Ag}_{3}\left(\mathrm{~S}-{ }^{t} \mathrm{C}_{4} \mathrm{H}_{9}\right)_{18}\right]^{2+}$ in the ESI-MS spectrum of $\mathrm{Au}_{30-x} \mathrm{Ag}_{x}\left(\mathrm{~S}-{ }^{t} \mathrm{C}_{4} \mathrm{H}_{9}\right)_{18}(x=2-4)$. The mass peak intensity follows an order: $\mathrm{x}=2>\mathrm{x}=3>$ $\mathrm{x}=4$. 

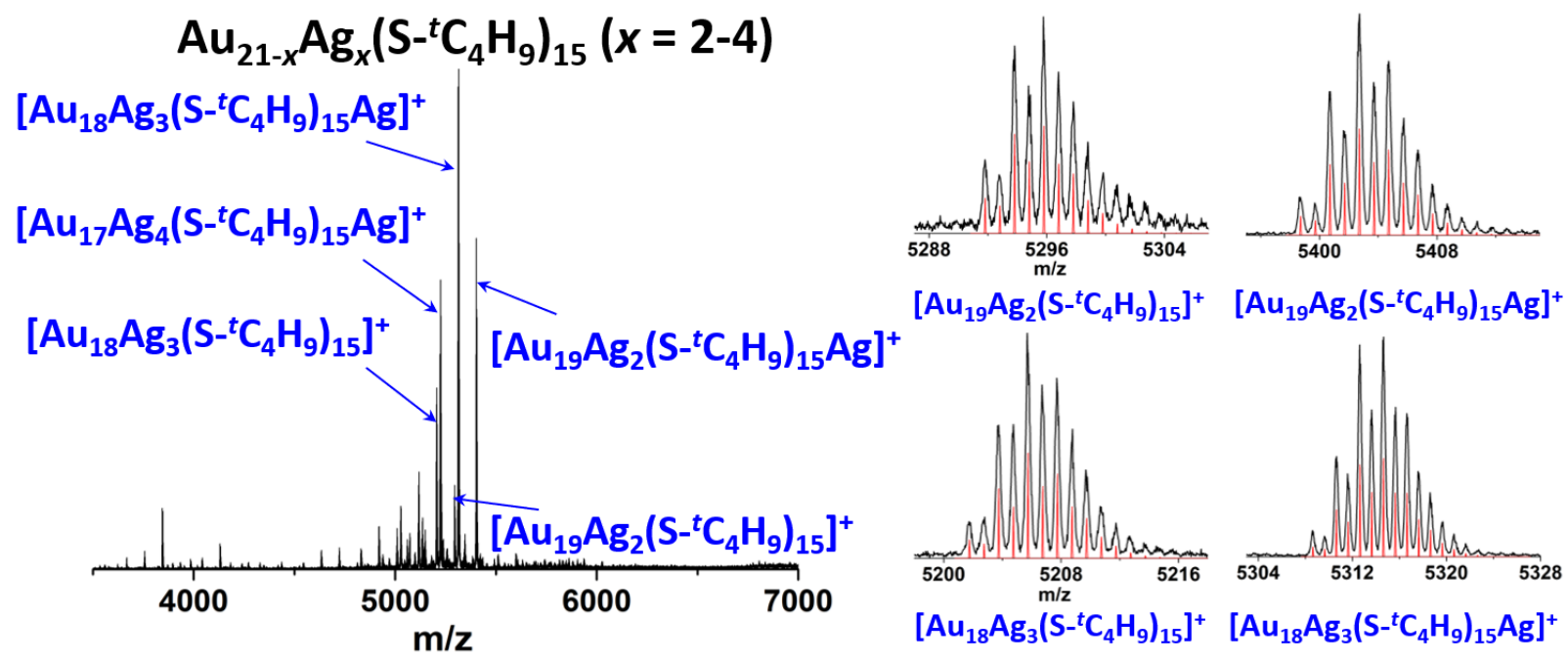

Figure S3. ESI-MS spectrum of $\mathrm{Au}_{21-x} \mathrm{Ag}_{x}\left(\mathrm{~S}_{-}{ }^{t} \mathrm{C}_{4} \mathrm{H}_{9}\right)_{15}(x=2-4)$, and the isotope peaks of $\left[\mathrm{Au}_{19} \mathrm{Ag}_{2}(\mathrm{SR})_{15}\right]^{+}, \quad\left[\mathrm{Au}_{19} \mathrm{Ag}_{2}(\mathrm{SR})_{15} \mathrm{Ag}\right]^{+},\left[\mathrm{Au}_{18} \mathrm{Ag}_{3}(\mathrm{SR})_{15}\right]^{+}$, and $\left[\mathrm{Au}_{18} \mathrm{Ag}_{3}(\mathrm{SR})_{15} \mathrm{Ag}\right]^{+}$. A set of peaks corresponding to $\left[\mathrm{Au}_{21-x} \mathrm{Ag}_{x}(\mathrm{SR})_{15} \mathrm{Ag}\right]^{+}$is observed along with another set of peaks corresponding to $\left[\mathrm{Au}_{21-x} \mathrm{Ag}_{x}(\mathrm{SR})_{15}\right]^{+}$. All the peaks are corresponding to the $1^{+}$ions, evidenced by the unity spacing of peaks. The phenomenon that a Ag cation can be picked up by the cluster during ESI-MS was previously reported for $\mathrm{Au}_{21-x} \mathrm{Ag}_{x}(\mathrm{SR})_{15}(x=1$, or $4-8)$ of the same structure. ${ }^{\mathrm{s} 1}$
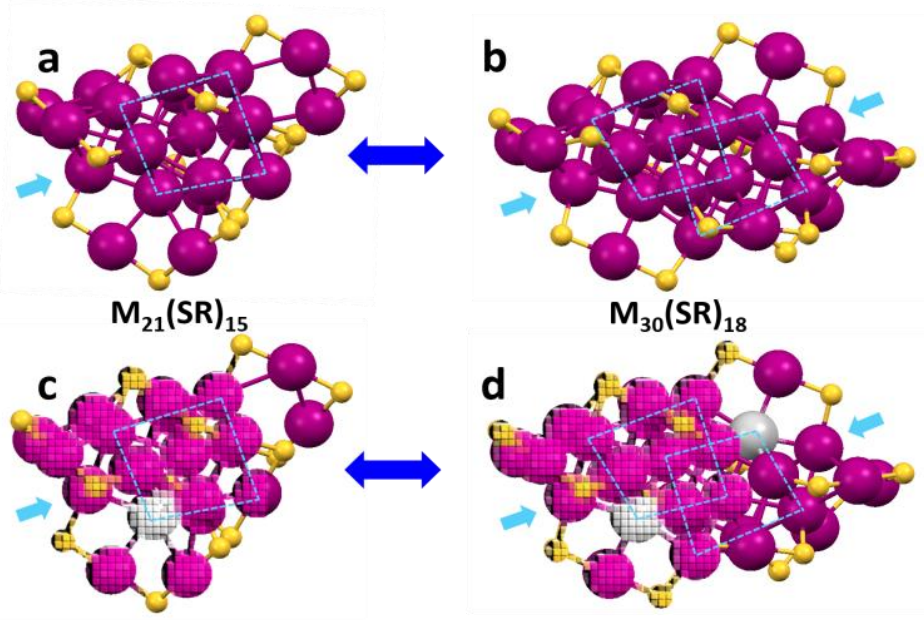

Figure S4. Structural comparisons between (a) $A u_{21}(S R)_{15}$ and (b) $A u_{30}(S R)_{18}$; (c) $A u_{20} A g_{1}(S R)_{15}$ and (d) $\mathrm{Au}_{28} \mathrm{Ag}_{2}(\mathrm{SR})_{18}$. Labels: magenta $=\mathrm{Au}$, yellow $=\mathrm{S}, \mathrm{C}$ and $\mathrm{H}$ are eliminated for clarity. 

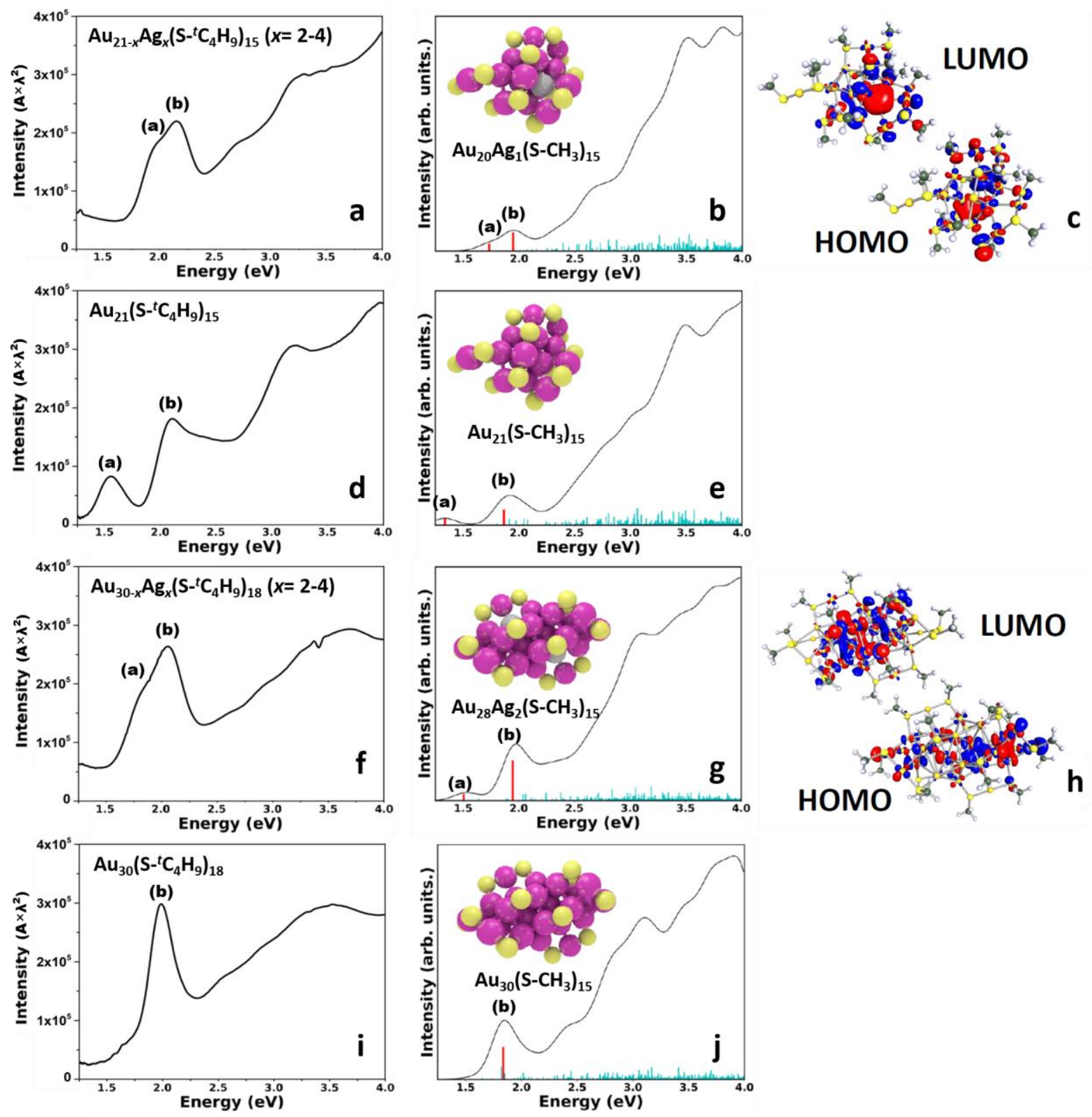

Figure S5. Experimental and theoretical absorption spectra for $(\mathrm{a} / \mathrm{b}) \mathrm{Au}_{21-x} \mathrm{Ag}_{x}\left(\mathrm{~S}^{-t} \mathrm{C}_{4} \mathrm{H}_{9}\right)_{15}(x=2$ 4) $/ \mathrm{Au}_{20} \mathrm{Ag}_{1}\left(\mathrm{~S}-\mathrm{CH}_{3}\right)_{15}$, (d/e) $\mathrm{Au}_{21}\left(\mathrm{~S}-{ }^{-} \mathrm{C}_{4} \mathrm{H}_{9}\right)_{15} / \mathrm{Au}_{21}\left(\mathrm{~S}-\mathrm{CH}_{3}\right)_{15}$, (f/g) $\mathrm{Au}_{30-x} \mathrm{Ag}_{x}\left(\mathrm{~S}-{ }^{t} \mathrm{C}_{4} \mathrm{H}_{9}\right)_{18} \quad(x=2-4) /$ $\mathrm{Au}_{28} \mathrm{Ag}_{2}\left(\mathrm{~S}-\mathrm{CH}_{3}\right)_{18}$, and $(\mathrm{i} / \mathrm{j}) \mathrm{Au}_{30}\left(\mathrm{~S}-\mathrm{t}_{4} \mathrm{H}_{9}\right)_{18} / \mathrm{Au}_{30}\left(\mathrm{~S}-\mathrm{CH}_{3}\right)_{18}$. The visualized diagrams of HOMO and LUMO for (c) $\mathrm{Au}_{20} \mathrm{Ag}_{1}\left(\mathrm{~S}-\mathrm{CH}_{3}\right)_{15}$ and (h) $\mathrm{Au}_{28} \mathrm{Ag}_{2}\left(\mathrm{~S}-\mathrm{CH}_{3}\right)_{18}$. 


\section{Au:Ag = 10:1; toluene:HS- ${ }^{t} \mathrm{C}_{4} \mathrm{H}_{9}=1: 1.5,45^{\circ} \mathrm{C}$}
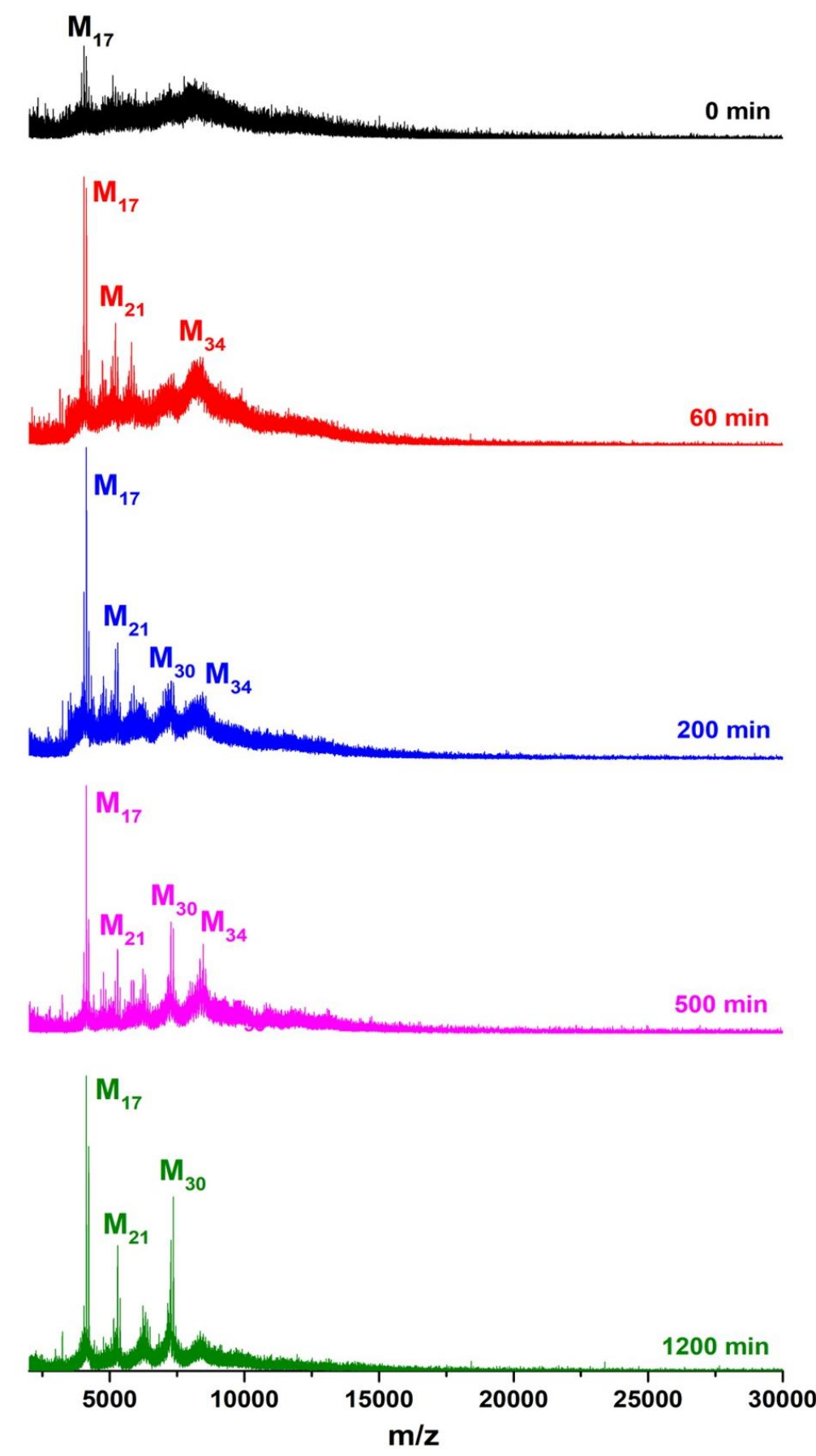

Figure S6. Time dependent MALDI-MS spectra of the sample by reacting the crude product obtained in step I (initial molar ratio of $\mathrm{Au}: \mathrm{Ag}=10: 1)$ in a mixture of toluene and $\mathrm{HS}^{t} \mathrm{C}_{4} \mathrm{H}_{9}(\mathrm{v}: \mathrm{V}=$ $1: 1.5$ ) at $45^{\circ} \mathrm{C}$ for total $1200 \mathrm{~min}$. 


\section{Au:Ag $=10: 1$; toluene: $\mathrm{HS}_{-}{ }^{t} \mathrm{C}_{4} \mathrm{H}_{9}=1: 1.5,45^{\circ} \mathrm{C}$}

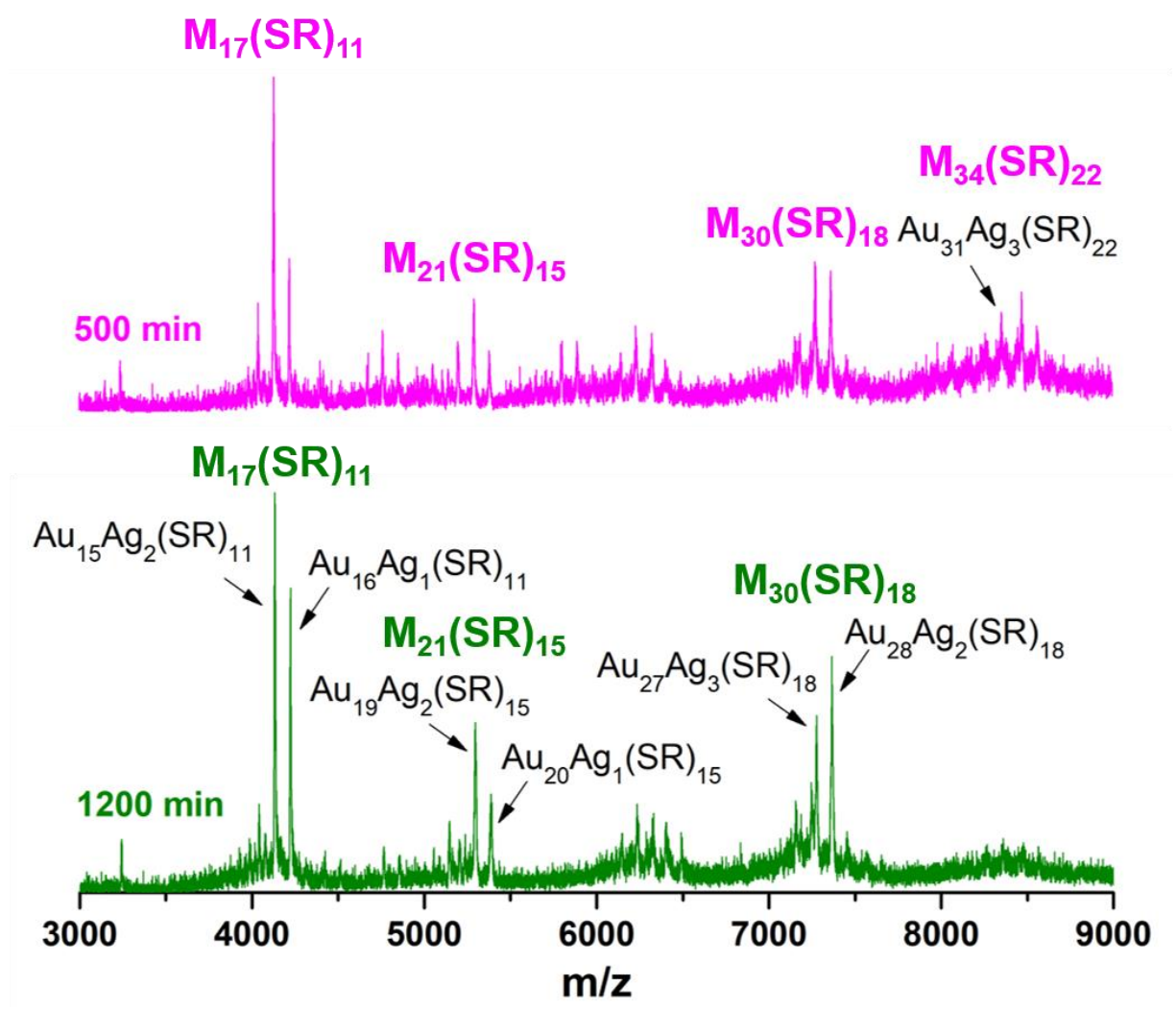

Figure S7. The enlarged MALDI-MS spectra of Figure S6 for the sample reacted for 500 min and $1200 \mathrm{~min}$, respectively. 


\section{Au:Ag = 10:1; toluene:HS- ${ }^{t} \mathrm{C}_{4} \mathrm{H}_{9}=1: 1.5, \mathrm{RT}$}
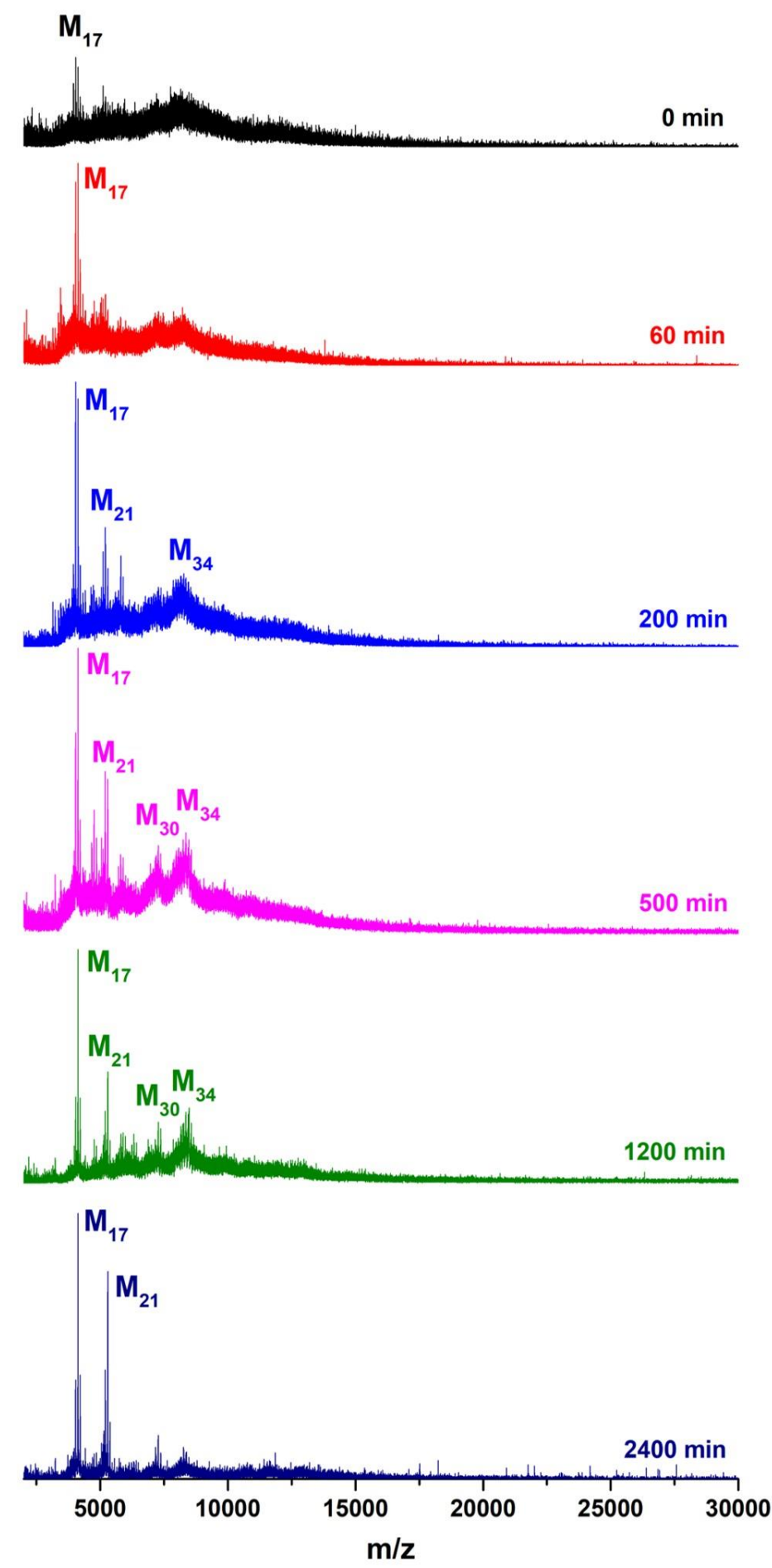

Figure S8. Time dependent MALDI-MS spectra of the sample by reacting the crude product obtained in step I (initial molar ratio of $\mathrm{Au}: \mathrm{Ag}=10: 1)$ in a mixture of toluene and $\mathrm{HS}^{-} \mathrm{C}_{4} \mathrm{H}_{9}(\mathrm{v}: \mathrm{V}=$ 1:1.5) at room temperature for total $2400 \mathrm{~min}$. 


\section{$A u: A g=10: 1 ;$ toluene:HS- ${ }^{t} C_{4} H_{9}=1: 1.5, R T$}

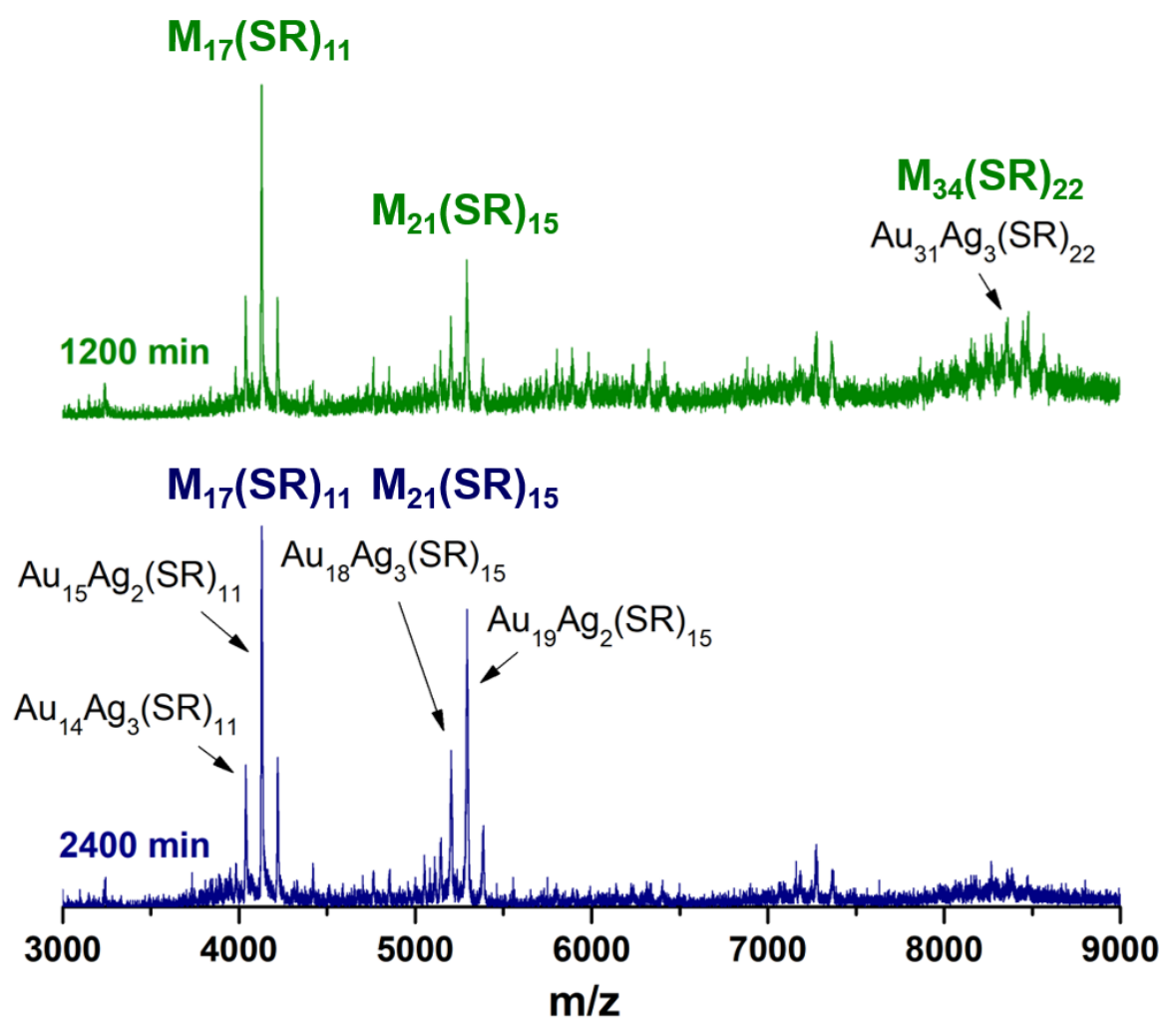

Figure S9. The enlarged MALDI-MS spectra of Figure S8 for the sample reacted for 1200 min and $2400 \mathrm{~min}$, respectively. 


\section{$\mathrm{Au}: \mathrm{Ag}=10: 1 ;$ toluene: $\mathrm{HS}-{ }^{t} \mathrm{C}_{4} \mathrm{H}_{9}=1: 3,45^{\circ} \mathrm{C}$}
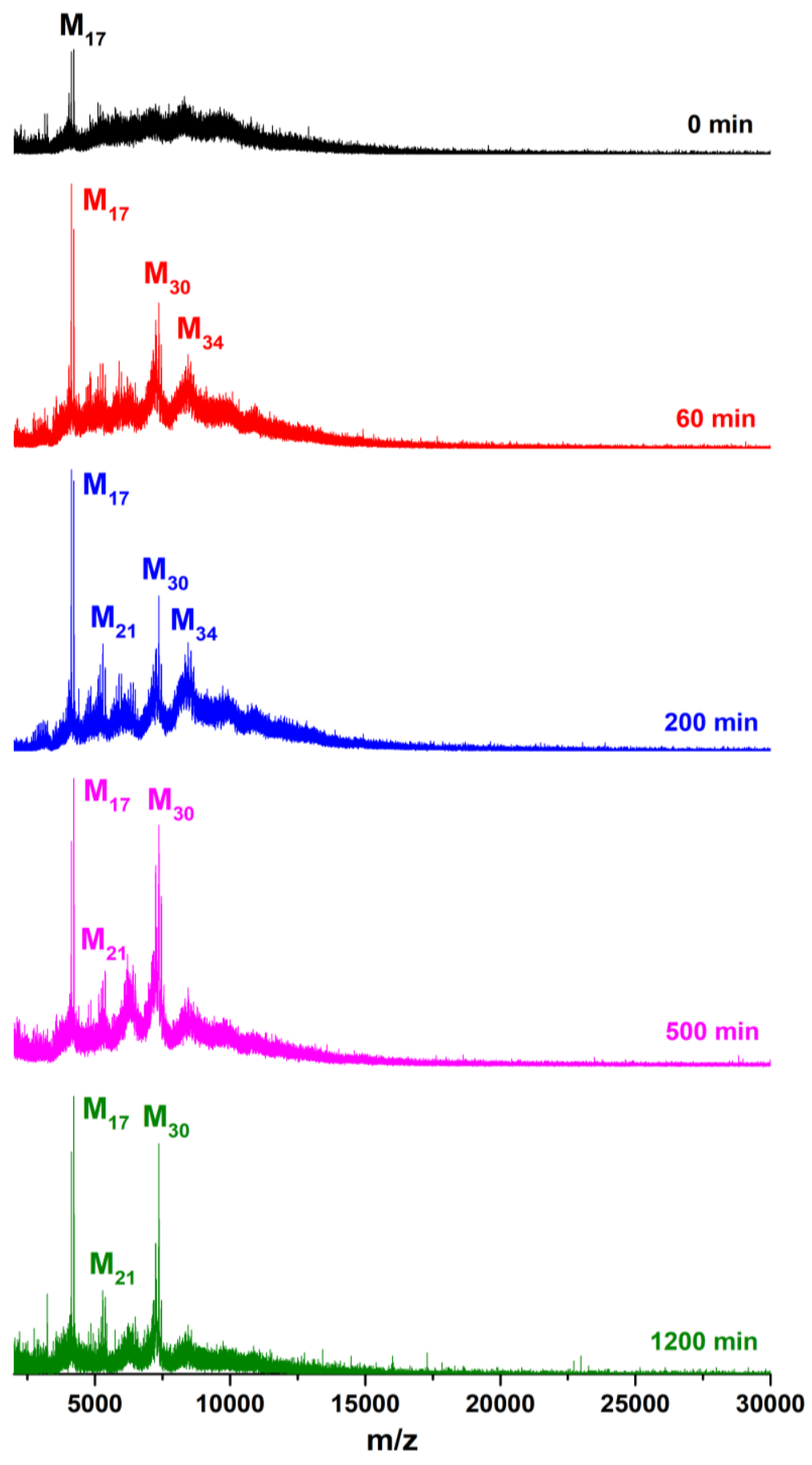

Figure S10. Time dependent MALDI-MS spectra of the sample by reacting the crude product obtained in step I (initial molar ratio $\mathrm{Au}: \mathrm{Ag}=10: 1)$ in a mixutre of toluene and $\mathrm{HS}-{ }^{t} \mathrm{C}_{4} \mathrm{H}_{9}(\mathrm{v}: \mathrm{v}=1: 3)$ at $45^{\circ} \mathrm{C}$ for total 1200 minutes. 


\section{$A u: A g=10: 1 ;$ toluene: $H S-{ }^{t} C_{4} H_{9}=1: 3,45^{\circ} \mathrm{C}$}

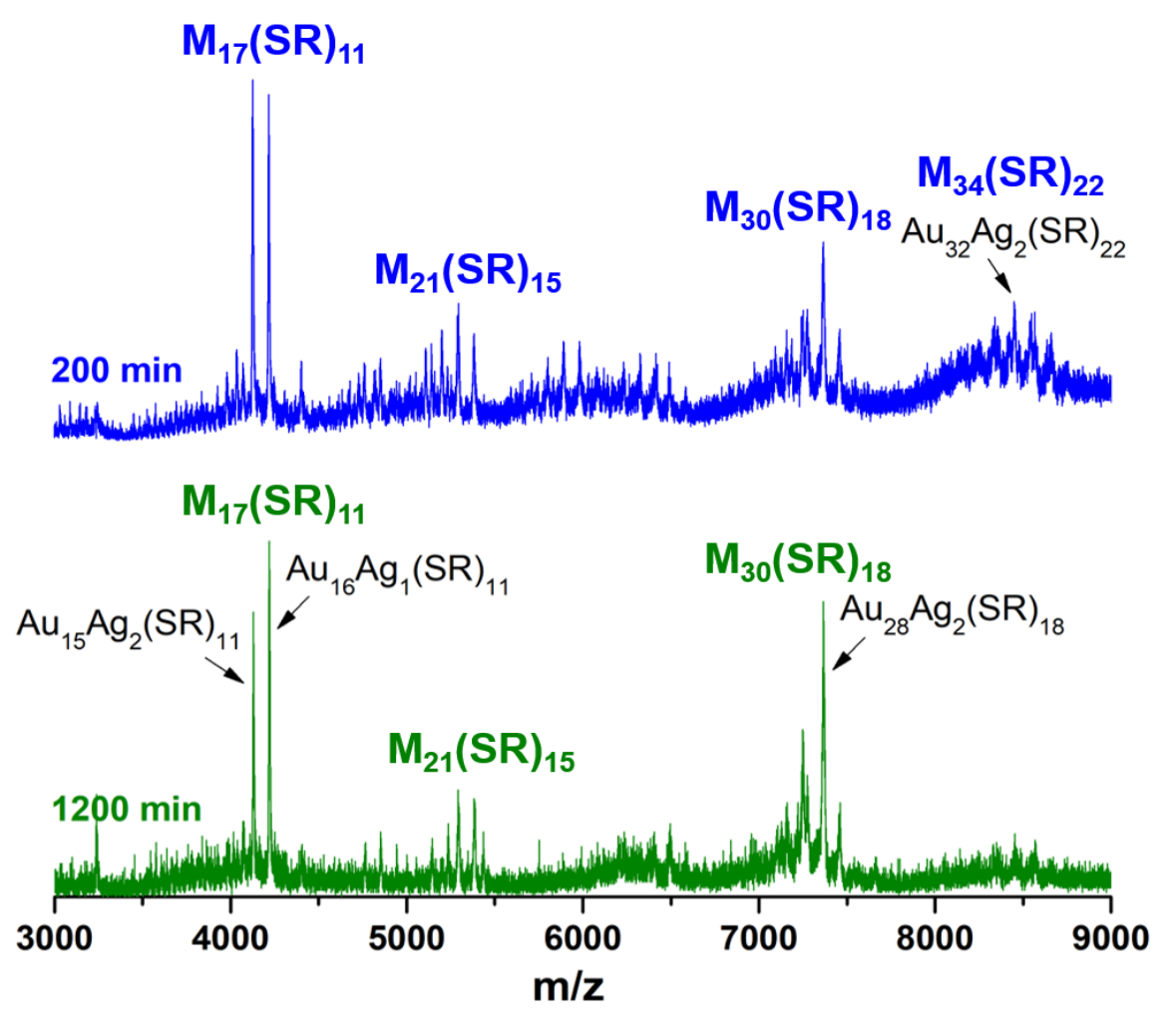

Figure S11. The enlarged MALDI-MS spectra of Figure S10 for the sample reacted for 200 min and $500 \mathrm{~min}$, respectively. 


\section{$\mathrm{Au}: \mathrm{Ag}=15: 1 ;$ toluene: $\mathrm{HS}^{-}{ }^{t} \mathrm{C}_{4} \mathrm{H}_{9}=1: 3,45^{\circ} \mathrm{C}$}
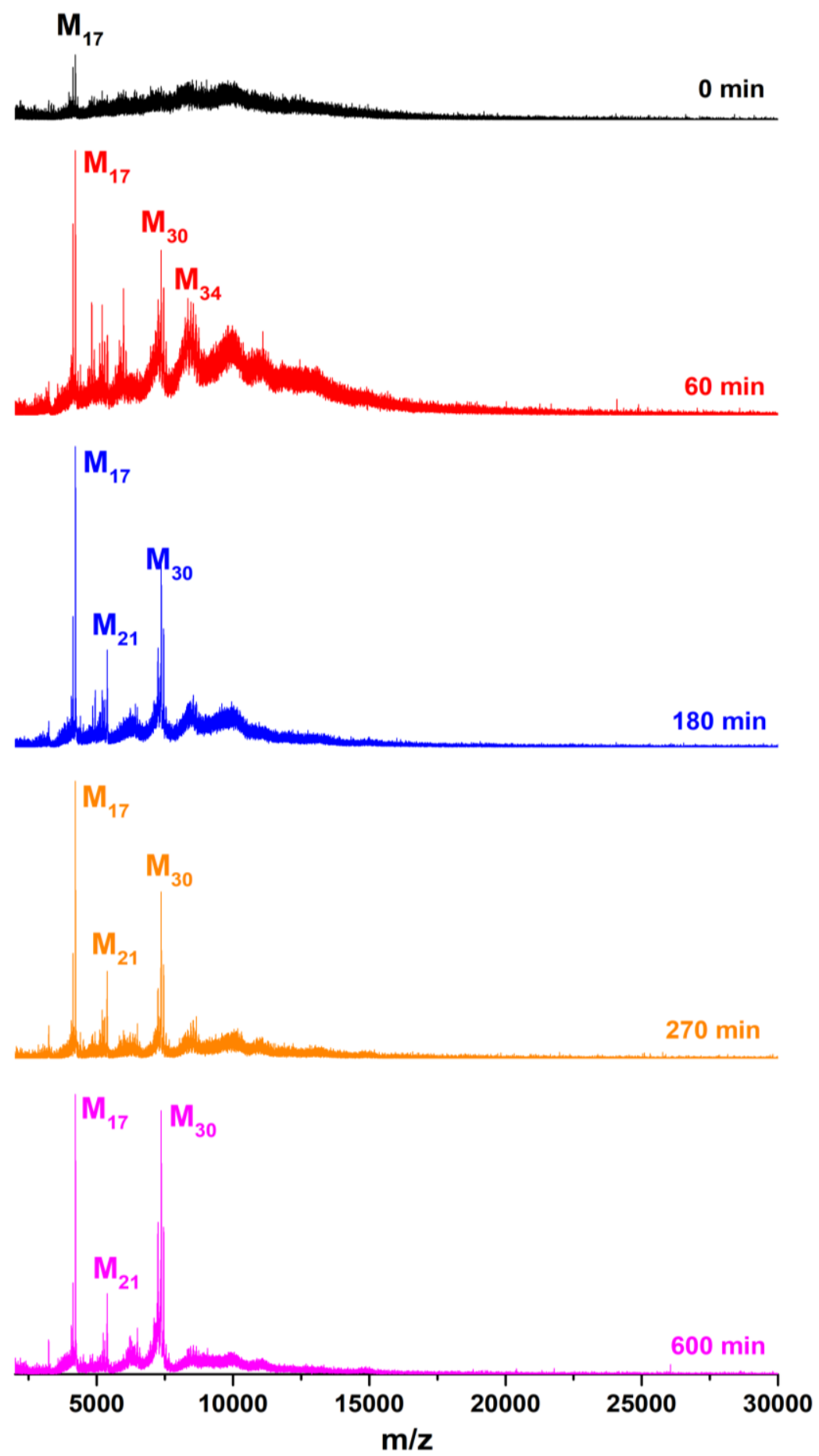

Figure S12. Time dependent MALDI-MS of the sample obtained in step I (initial molar ratio of $\mathrm{Au}: \mathrm{Ag}=15: 1)$ and reacted in the mixture of toluene and $\mathrm{HS}-{ }^{-} \mathrm{C}_{4} \mathrm{H}_{9}(\mathrm{v}: \mathrm{V}=1: 3)$ at $45{ }^{\circ} \mathrm{C}$ for total 600 $\min$. 


\section{$A u: A g=15: 1 ;$ toluene: $\mathrm{HS}^{-}{ }^{t} \mathrm{C}_{4} \mathrm{H}_{9}=1: 3,45^{\circ} \mathrm{C}$}

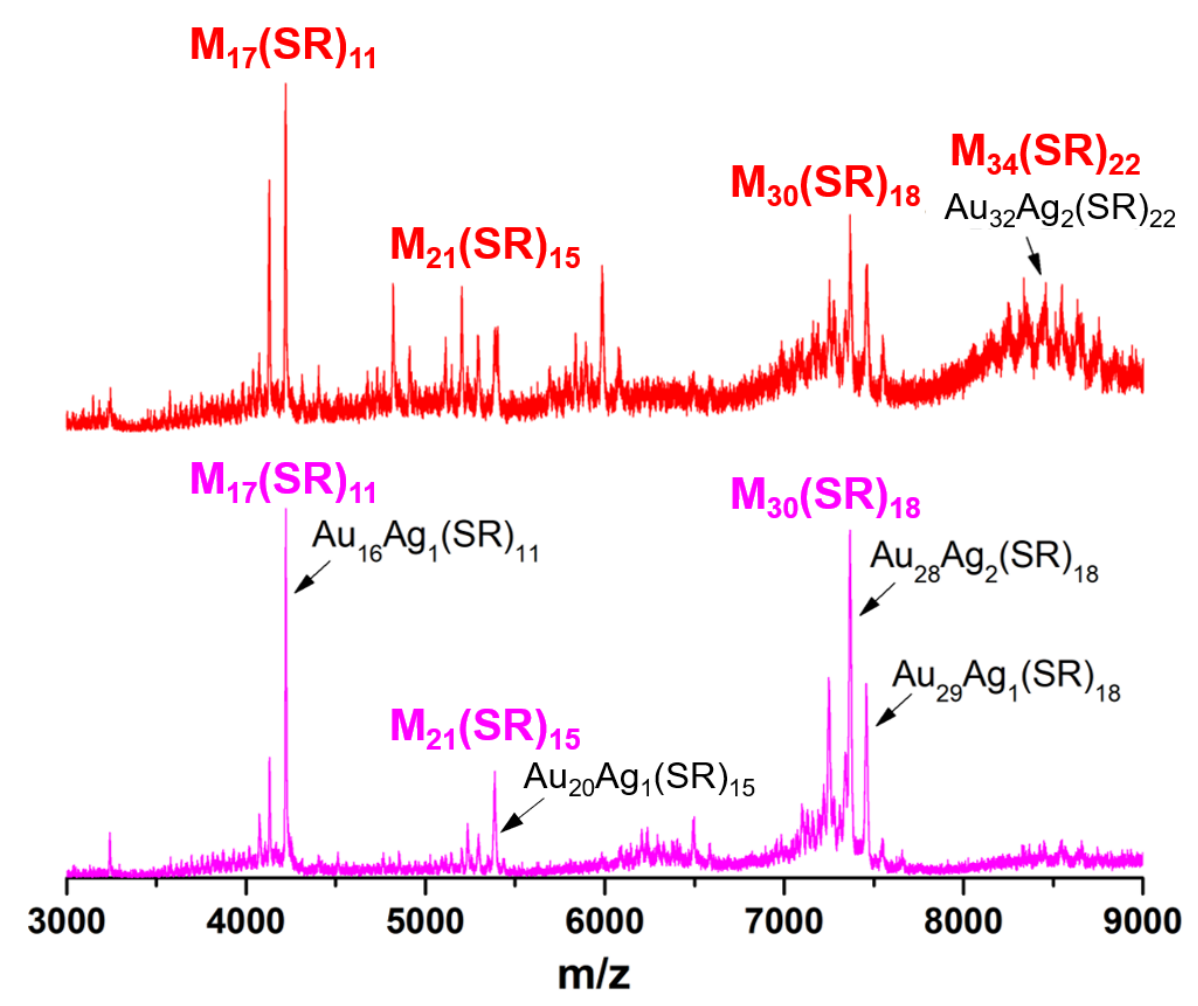

Figure S13. The enlarged MALDI-MS spectra of Figure S12 for the sample reacted for 60 min and $600 \mathrm{~min}$, respectively.

\section{Reference}

(s1) Yang, S.; Chai, J.; Song, Y.; Fan, J.; Chen, T.; Wang, S.; Yu, H.; Li, X.; Zhu, M. In Situ Two-Phase Ligand Exchange: A New Method for the Synthesis of Alloy Nanoclusters with Precise Atomic Structures. J. Am. Chem. Soc. 2017, 139, 5668-5671.

(s2) Crasto, D.; Dass, A. Green Gold: $\mathrm{Au}_{30}\left(\mathrm{~S}-t-\mathrm{C}_{4} \mathrm{H}_{9}\right)_{18}$ Molecules. J. Phys. Chem. C 2013, 117, $22094-22097$.

(s3) APEX2, SAINT, and SADABS, Bruker AXS Inc.: Madison WI, USA, 2014.

(s4) G. Sheldrick, SHELXT - Integrated Space-Group and Crystal-Structure Determination. Acta. Cryst. 2015, A71, 3-8.

(s5) G. Sheldrick, Crystal Structure Refinement with SHELXL. Acta. Cryst. 2015, C71, 3-8.

(s6) Dolomanov, 0. V.; Bourhis, L. J.; Gildea, R. J.; Howard, J. A.; Puschmann, H. OLEX2: A Complete Structure Solution, Refinement and Analysis Program. J. Appl. Crystallogr. 2009, 42, 339-341.

(s7) Weigend, F.; Häser, M.; Patzelt, H.; Ahlrichs, R. RI-MP2: Optimized Auxiliary Basis Sets and Demonstration of Efficiency. Chem. Phys. Lett. 1998, 294, 143-152.

(s8) Weigend, F.; Häser, M. RI-MP2: First Derivatives and Global Consistency. Theor. Chem. Acc. 1997, 97, 331-340.

(s9) Feyereisen, M.; Fitzgerald, G.; Komornicki, A. Use of Approximate Integrals in ab initio Theory. An Application in MP2 Energy Calculations. Chem. Phys. Lett. 1993, 208, 359-363. 
(s10) Zhu, M.; Eckenhoff, W. T.; Pintauer, T.; Jin, R. Conversion of Anionic $\left[\mathrm{Au}_{25}\left(\mathrm{SCH}_{2} \mathrm{CH}_{2} \mathrm{Ph}\right)_{18}\right]^{-}$ Cluster to Charge Neutral Cluster via Air Oxidation. J. Phys. Chem. C 2008, 112, 14221-14224.

(s11) Qian, H.; Eckenhoff, W. T.; Zhu, Y.; Pintauer, T.; Jin, R. Total Structure Determination of Thiolate-Protected $\mathrm{Au}_{38}$ Nanoparticles. J. Am. Chem. Soc. 2010, 132, 8280-8281.

(s12) Xiong, L.; Yang, S.; Sun, X.; Chai, J.; Rao, B.; Yi, L.; Zhu, M.; Pei, Y. Structure and Electronic Structure Evolution of Thiolate-Protected Gold Nanoclusters Containing Quasi Face-Centered-Cubic Kernels. J. Phys. Chem. C 2018, 122, 14898-14907.

(s13) Dass, A.; Jones, T.; Rambukwella, M.; Crasto, D.; Gagnon, K. J.; Sementa, L.; De Vetta, M.; Baseggio, O.; Aprà, E.; Stener, M.; Fortunelli, A. Crystal Structure and Theoretical Analysis of Green Gold $\mathrm{Au}_{30}(\mathrm{~S}-\mathrm{BBu})_{18}$ Nanomolecules and Their Relation to $\mathrm{Au}_{30} \mathrm{~S}(\mathrm{~S}-\mathrm{B} \mathrm{Bu})_{18}$. J. Phys. Chem. C 2016, 120, 6256-6261.

(s14) Zeng, C.; Li, T.; Das, A.; Rosi, N. L.; Jin, R. Chiral Structure of Thiolate-Protected 28-GoldAtom Nanocluster Determined by X-ray Crystallography. J. Am. Chem. Soc. 2013, 135, 10011-10013.

(s15) Zeng, C.; Chen, Y.; Iida, K.; Nobusada, K.; Kirschbaum, K.; Lambright, K. J.; Jin, R. Gold Quantum Boxes: On the Periodicities and the Quantum Confinement in the $\mathrm{Au}_{28}, \mathrm{Au}_{36}, \mathrm{Au}_{44}$, and $\mathrm{Au}_{52}$ Magic Series. J. Am. Chem. Soc. 2016, 138, 3950-3953.

(s16) Zeng, C.; Liu, C.; Chen, Y.; Rosi, N. L.; Jin, R. Gold-Thiolate Ring as a Protecting Motif in the $\mathrm{Au}_{20}(\mathrm{SR})_{16}$ Nanocluster and Implications. J. Am. Chem. Soc. 2014, 136, 11922-11925.

(s17) Zeng, C.; Qian, H.; Li, T.; Li, G.; Rosi, N. L.; Yoon, B.; Barnett, R. N.; Whettern, R. L.; Landman, U.; Jin, R. Total Structure and Electronic Properties of the Gold Nanocrystal $\mathrm{Au}_{36}(\mathrm{SR})_{24}$. Angew. Chem. Int. Ed. 2012, 51, 13114-13118.

(s18) Li, Q.; Luo, T.-Y.; Taylor, M. G.; Wang, S.; Zhu, X.; Song, Y.; Mpourmpakis, G.; Rosi, N. L.; Jin, R. Molecular "Surgery" on a 23-Gold-Atom Nanoparticle. Sci. Adv. 2017, 3:e1603193.

(s19) Ma, Z.; Wang, P.; Zhou, G.; Tang, J.; Li, H.; Pei, Y. Correlating the Structure and Optical Absorption Properties of $\mathrm{Au}_{76}(\mathrm{SR})_{44}$ Cluster. J. Phys. Chem. C 2016, 120, 13739-13748. 